\title{
O papel do psicólogo escolar: Concepções de professores e gestores
}

\author{
Nara Liana Pereira-Silva \\ Universidade Federal de Juiz de Fora - Juiz de Fora - MG - Brasil \\ Jaqueline Ferreira Condé de Melo Andrade \\ Universidade Federal de Juiz de Fora - Juiz de Fora - MG - Brasil \\ Sarah Rezende Crolman \\ Universidade Federal de Juiz de Fora - Juiz de Fora - MG - Brasil \\ Cristina Fuentes Mejía \\ Universidade Federal de Juiz de Fora - Juiz de Fora - MG - Brasil
}

\begin{abstract}
Resumo
Historicamente, a atuação do psicólogo no contexto escolar tem sido mais caracterizada pelo modelo clínico do que por modelos mais sistêmicos e institucionais. O presente estudo objetivou descrever as concepções de professores e gestores sobre o papel do psicólogo escolar. Participaram desta investigação 38 membros da equipe administrativo-pedagógica e professores de uma escola particular, os quais foram entrevistados na própria escola, tendo sido construídas categorias de análise. Os resultados mostram que gestores e professores concebem o psicólogo escolar como um 'especialista', mas também como um profissional 'auxiliar'. Além disso, houve relatos de desconhecimento das funções do psicólogo. Segundo os participantes, o psicólogo deve atuar primordialmente junto aos alunos. Concepções similares foram encontradas em outros estudos, apesar de se reconhecer a existência de críticas a essa modelo. Destaca-se a importância de intervenções com o foco na prevenção e promoção do desenvolvimento.
\end{abstract}

Palavras-chave: psicólogo escolar; educação; psicologia escolar.

\section{The role of scholar psychologist: Conceptions of teachers and managers}

\begin{abstract}
Historically, the performance of the psychologist in the school context has been characterized by the clinical model rather than by more systemic and institutional models. The present study aimed to describe the teachers' and managers' conceptions about the role of the school psychologist. Thirty-eight members of the administrative-pedagogical team and teachers of a private school participated in this research, which were interviewed in the school itself, and categories of analysis were constructed. The results show that managers and teachers think the school psychologist as a 'specialist', but also as an 'auxiliary' professional. In addition, there were reports of ignorance of the functions of the psychologist. According to the participants, the psychologist should act primarily with the students. Similar concepts were found in other studies, despite the acknowledgment of criticisms of this model. It is important to emphasize the importance of interventions with a focus on prevention and promotion of development.
\end{abstract} Keywords: school psychologist; education; school psychology.

\section{El papel del psicólogo escolar: concepciones de profesores y gestores}

\section{Resumen}

Históricamente, la actuación del psicólogo en el contexto escolar ha sido más caracterizada por el modelo clínico de que por modelos más sistémicos e institucionales. En el presente estudio se tuvo el objetivo describir las concepciones de profesores y gestores sobre el papel del psicólogo escolar. Participaron de esta investigación 38 miembros del equipo administrativo-pedagógico y profesores de una escuela particular, los cuales fueron entrevistados en la propia escuela, se construyeron categorías de análisis. Los resultados muestran que gestores y profesores conciben el psicólogo escolar como un 'especialista', pero también como un profesional 'auxiliar'. Además de eso, hubo relatos de desconocimiento de las funciones del psicólogo. Según los participantes, el psicólogo debe actuar primordialmente junto a los alumnos. Concepciones similares se encontraron en otros estudios, a pesar de reconocerse la existencia de críticas a ese modelo. Se destaca la importancia de intervenciones con enfoque en la prevención y promoción del desarrollo.

Palabras clave: psicólogo escolar; educación; psicología escolar. 


\section{Introdução}

A relação entre as áreas da Psicologia e da Educação, no Brasil, é antiga e merece destaque, uma vez que foi no campo da Educação que a Psicologia realizou suas primeiras aplicações (Antunes, 2002, 2008, 2012; Goulart, 2003). A prática psicológica no contexto escolar, especialmente no Brasil, esteve, inicialmente, baseada no paradigma positivista (Antunes, 2012; Carvalho \& Marinho-Araújo, 2009), estando em consonância com as transformações políticas norteadas por concepções liberais ocorridas no país no início da República. Segundo Oliveira e Marinho-Araújo (2009), a construção da relação Psicologia-Educação foi fortemente marcada por ações que tinham o objetivo de adaptar o indivíduo ao contexto escolar, com a utilização de psicodiagnósticos e avaliação psicológica.

O modelo clínico de atuação predominava, apresentando-se descontextualizado em relação às necessidades da escola e fundamentado em ideias norte-americanas e europeias (Antunes, 2012; Barbosa, 2010; Carvalho \& Marinho-Araújo, 2009). O resultado foi o desenvolvimento de um exercício psicológico que enfatizava a avaliação das dificuldades de aprendizagem de crianças e adolescentes por meio de instrumentos padronizados (Andaló, 1984; Antunes, 2008; Guzzo, Mezzalira, Moreira, Tizzei, \& Neto, 2010; Lima, 2005), atribuindo unicamente aos indivíduos e às suas famílias a responsabilidade pelo fracasso escolar (Antunes, 2008). Nesse tipo de atuação o aluno é 'culpado' por sua não aprendizagem, excluindo-se os fatores intra-escolares e as questões sociais na promoção das dificuldades e do fracasso escolar. Atualmente, há críticas a esse modelo como prática psicológica dentro da escola havendo, por parte dos psicólogos, a ampliação e o aperfeiçoamento de intervenções nesse contexto, com o intuito de problematizar e reverter dinâmicas institucionais produtoras de fracasso escolar e de encaminhamentos de alunos para atendimento psicológico (Firbida \& Facci, 2015; Lessa \& Facci, 2011; Souza, 2007; Souza, 2009; Souza, Gomes, Cecchia, Lara, \& Roman, 2016). Há, portanto, necessidade de redimensionar a atuação do psicólogo escolar e de empreender atividades promotoras de saúde e de desenvolvimento humano na educação, conforme ressalta a literatura (Cruces, 2005; Rodrigues, Itaborahy, Pereira, \& Gonçalves, 2008; Rossetti, Silva, Batista, Stein, \& Hulle, 2004; Souza \& cols., 2016).

A partir dos anos de 1970, de acordo com Antunes (2008), se identificam críticas ao modelo médico de atuação do psicólogo escolar, com foco nos problemas dos alunos. A partir de então e, principalmente, dos anos 2000 observam-se estudos que mostram a importância e a necessidade de uma atuação mais preventiva, interdisciplinar e por uma Psicologia Escolar mais crítica (Antunes, 2008; Lessa \& Facci, 2011; Souza \& cols., 2016). Por exemplo, no trabalho de Neves, Almeida, Chaperman e Batista (2002), as autoras afirmam que o psicólogo escolar ainda não consolidou seu espaço de atuação profissional, existindo a necessidade de redefinição do seu papel nas instituições escolares visando, sobretudo, o exercício de uma prática psicológica integrada com a realidade brasileira, em uma perspectiva mais preventiva e interdisciplinar. Na investigação de Souza, Ribeiro e Silva (2011) acerca da atuação dos psicólogos escolares na rede privada de ensino foram identificadas práticas tradicionais e emergentes. Segundo as autoras, "o psicólogo pode ampliar o alcance de sua atuação, desde que esteja fundamentado em concepções que considerem a dimensão histórico-cultural da constituição humana" (p. 57).

No estudo realizado nos Estados Unidos por Watkins, Crosby e Pearson (2001), com 522 profissionais da equipe escolar, a função predominante do psicólogo escolar, segundo a equipe, era a de avaliação dos alunos. Os profissionais avaliaram como 'muito importante' as atividades de avaliação, de acompanhamento na inserção do aluno na educação especial, de consulta e aconselhamento e, também, para as intervenções em momentos de crise e manejo comportamental. Os entrevistados relataram que o psicólogo escolar realizava um bom trabalho, considerando o tempo dedicado à escola, mas os participantes enfatizaram que ainda havia necessidade dos serviços psicológicos, o que indica uma valorização do trabalho do psicólogo escolar e uma crescente demanda, o que pode acarretar excesso de trabalho. Watkins e cols. (2001) constataram que os psicólogos escolares desejavam realizar atividades mais diversificadas, no entanto, havia solicitação frequente pela avaliação dos alunos.

Os resultados de Giongo e Oliveira-Menegotto (2010), no cenário nacional, reforçam os resultados encontrados por Watkins e cols. (2001), mesmo em contextos culturais diferentes. Giongo e Oliveira-Menegotto mostraram que os professores de escolas públicas de uma cidade do interior do Rio Grande do Sul atribuem ao psicólogo escolar a função de diagnosticar, revelando expectativas de que o psicólogo exerça funções clínicas no contexto escolar. Aliada a essas concepções, identificaram-se outras que denotam a concepção de centralização dos 'problemas' no aluno. Segundo Giongo e Oliveira-Menegotto, esses dados evidenciam o desconhecimento do papel do psicólogo escolar por parte dos professores. As autoras ressaltam a importância de um trabalho interdisciplinar, o qual esteve ausente nos relatos dos professores entrevistados.

Em um estudo mais recente sobre o papel do psicólogo escolar, realizado no Chile, os resultados de Costa, Sanhueza, Barra e Villalobos (2012) demonstraram que, inicialmente, a comunidade escolar não tinha clareza quanto ao papel desse profissional. Costa e cols. (2012, p. 176) afirmam que

ocorre uma confusão com o papel a desempenhar, já que muitas vezes se pensa que o psicólogo vem exercer um papel clínico. Isto influencia a maneira na qual o psicólogo está incluído dentro do estabelecimento, dado que deve esclarecer estas dúvidas, ir progressivamente colocando limites e focalizando as expectativas da comunidade educativa, que, de acordo com os psicólogos, é uma tarefa desgastante. 
Após a inserção do psicólogo na escola, a sua atuação foi descrita pelos participantes como sendo junto aos alunos. O papel do psicólogo seria o de resolver os problemas dos alunos, a partir da solicitação dos professores e gestores, seja no nível individual ou grupal, tendo autonomia na escolha e na implementação das estratégias. As análises mostraram que os problemas mais comumente relatados foram: problemas comportamentais, bullying e dificuldades na convivência escolar. Os autores apontam que esse tipo de atuação do psicólogo deriva do fato de que a comunidade escolar não identifica outras funções para o psicólogo, uma vez que ela não tem uma representação prévia do que o psicólogo escolar pode fazer. Mas também os psicólogos investigados não tinham clareza sobre o que fazer no contexto escolar.

Similar às conclusões de Costa e cols. (2012) no contexto de uma escola do Chile, no estudo brasileiro de Rossetti, Silva, Batista, Stein e Hulle (2004), na cidade de Vitória, os profissionais da educação (com exceção do psicólogo escolar) do sistema público e privado, afirmaram que conhecem o trabalho do psicólogo, apesar de esse conhecimento estar relacionado a uma noção estereotipada e limitada da atuação de um profissional de psicologia em uma escola. Os resultados categorizados como "ênfase nos relacionamentos" apontavam para atendimentos individuais e/ou clínicos, especialmente no tocante aos estudantes. Segundo os autores, a imagem do campo da psicologia escolar, bem como dos psicólogos que atuam na área, era como "corpos estranhos" à rotina da escola. No caso do estudo de Bray (2015), com psicólogos da rede privada de ensino do estado de São Paulo, a atuação destes era junto a estudantes, pais e professores e, apesar dos profissionais afirmarem não utilizar o modelo clínico, também não se pode afirmar que havia uma atuação institucional e crítica, uma vez que predominava a perspectiva mais individualizada da prática do psicólogo.

Marinho-Araújo e Almeida (2005) reafirmam a importância da dimensão preventiva na atuação do psicólogo escolar. De acordo com as autoras, nessa perspectiva estão implicadas ações e estratégias para que o psicólogo escolar facilite e incentive a construção de procedimentos de ensino diversificados, promovendo a reflexão e conscientização de funções, papéis e responsabilidades dos sujeitos em interação no contexto escolar, além de buscar, junto com a equipe escolar, a superação dos obstáculos à apropriação do conhecimento. O foco na prevenção e promoção de saúde também é destacado por Rodrigues e cols. (2008), para os quais "a promoção de saúde constitui uma estratégia fundamental no contexto escolar, parte-se da necessidade de buscar o desenvolvimento global do indivíduo, estimulando suas competências e favorecendo sua integração junto à comunidade" (p. 69). A partir desse posicionamento, o papel do psicólogo no contexto escolar, portanto, deve ser pautado por ações que objetivem e promovam o desenvolvimento dos alunos em processo de escolarização. Considerando a diversidade existente na escola contemporânea, os psicólogos escolares precisam desenvolver estratégias diante de diferentes situações, por exemplo, aquelas que envolvem diversidade racial e étnica (Graves Jr., Procton, \& Aston, 2014), o bullying (Kub \& Feldman, 2015; Sherer \& Nickerson, 2010) e necessidades emocionais e comportamentais severas (McGraw \& Koonce, 2011).

De acordo com a literatura, o psicólogo deve atuar de forma sistêmica e abrangente, focalizando os diferentes atores sociais na escola (Farrell, 2009; McGraw \& Koonce, 2011). Guzzo (2003) ressalta que o atendimento dirigido somente ao estudante não assegura a sua "volta" aos ritmos de seu desenvolvimento integrado à sala de aula, família e comunidade, sugerindo que qualquer intervenção considere os diversos sistemas em que as crianças e/ou os adolescentes estão inseridos. A autora propõe a utilização de uma abordagem ecológica de atuação, destacando a prevenção e a promoção da saúde e do bem-estar subjetivo, permitindo aos estudantes obterem sucesso em suas atividades de vida, diminuindo o curso da violência, do fracasso escolar, da gravidez precoce dentre outros comportamentos considerados de risco ao desenvolvimento saudável. Além desses aspectos, espera-se que o psicólogo compreenda a importância da integração de seu trabalho com outros sistemas que influenciam o desenvolvimento da criança, especialmente, a família, a escola e a comunidade (Farrel, 2009).

Assim, nessa perspectiva, a Psicologia dentro da Escola deve estar engajada ao processo pedagógico, dando suporte ao trabalho com os demais profissionais. Ressalta-se que esse tipo de trabalho só será possível na medida em que todos os atores sociais tiverem clareza do seu papel e função (Farrell, 2009). Portanto, investigar as concepções de professores e gestores educacionais sobre a atuação do psicólogo na escola é um dos primeiros passos para se refletir acerca da atuação desse profissional e, em especial, no setor privado. Tendo os pressupostos sistêmicos e bioecológicos como norteadores, o presente estudo objetivou descrever as concepções sobre o papel do psicólogo escolar de professores e gestores de uma escola particular do interior do estado de Minas Gerais.

\section{Método}

\section{Participantes}

Participaram da pesquisa 38 membros da equipe administrativo-pedagógica e professores de uma escola particular do interior de Minas Gerais, dos quais 33 eram professores e cinco membros da equipe administrativo-pedagógica.

Os participantes tinham idades entre 21 e 66 anos, sendo 29 do sexo feminino e nove do sexo masculino. Quanto à formação acadêmica, a maioria possuía graduação (n = 30; $80 \%$ ), apenas dois o ensino médio, um o magistério e cinco estavam cursando a graduação. Desse total, $42 \%$ ( $n=16)$ possuíam especialização e 10,5\% ( $n=4)$ haviam concluído o mestrado. Dentre os participantes que possuíam graduação, 43\% ( $n=13)$ haviam se formado entre um a 
cinco anos, $23 \%(n=7)$ entre seis a dez anos, $17 \%(n=5)$ entre 11 a 20 e $17 \%(n=5)$ entre 25 a 35 anos.

No que tange ao tempo de trabalho na área da educação, 12 ( $n=12,31,6 \%$ ) possuíam entre seis meses a cinco anos de experiência, $29 \%(n=11)$ entre seis a 10 anos, $18,4 \%(n=7)$ entre 11 a 20 anos, $10,5 \%(n=4)$ entre 21 a 30 anos e 10,5\% ( $n=4)$ entre 31 a 34 anos. Quanto ao tempo de trabalho na instituição pesquisada, $74 \%(n=28)$ dos profissionais possuíam entre um a cinco anos de vínculo com a escola, $16 \%$ entre seis a 10 anos, 6\% entre 11 a 20 anos e $4 \%$ entre 21 a 34 . Mais da metade $(n=22 ; 58 \%)$ dos participantes trabalhava apenas nesta escola, os demais se dedicavam também a outras instituições de ensino, havendo profissionais com vínculo com até cinco instituições. Cabe ressaltar que a escola contava, à época da pesquisa, com um psicólogo escolar, o qual não participou como informante no presente estudo, uma vez que o objetivo era investigar a percepção de professores e gestores acerca do papel do psicólogo naquele contexto.

O critério utilizado para a composição da amostra foi a) fazer parte do corpo de professores, gestores ou da coordenação da escola, b) o consentimento para participar da pesquisa e c) permissão para a gravação em áudio da entrevista.

\section{Instrumentos}

Foi utilizada uma entrevista semiestruturada e um questionário sociodemográfico. A entrevista teve como foco a indagação "Qual é o papel do Psicólogo Escolar?", tendo se desdobrado, para fins de aprofundamento das respostas, em mais duas perguntas: "O que faz um psicólogo escolar?", "O que deve fazer um psicólogo escolar?" Esse tipo de estratégia de entrevista adota a forma de um diálogo coloquial, segundo Martinez (2006). Para Valles (1999) este é um tipo de entrevista conversacional informal que inicia com uma pergunta ampla de modo a não induzir respostas dos participantes. Cabe ressaltar que a entrevista se constitui em um método que "favorece o acesso direto ou indireto às opiniões, às crenças, aos valores e aos significados que as pessoas atribuem a si, aos outros e ao mundo circundante" (Fraser \& Gondim, 2004, p. 140). Já o questionário sociodemográfico objetivou caracterizar a amostra de participantes no que se refere ao sexo, idade, tempo de formação, tempo de profissão, tempo de trabalho na instituição investigada, bem como quantidade de empregos.

\section{Procedimentos}

Após a aprovação do projeto pelo Comitê de Ética em Pesquisa com Seres Humanos ${ }^{1}$, deu-se início à seleção, por conveniência, da escola e dos profissionais. Foi solicitado o consentimento dos participantes para a realização da entrevista, tendo sido estas realizadas individualmente

1 Universidade Federal de Juiz de Fora, sob o parecer $n^{\circ} 522.816$. na própria instituição, de acordo com a disponibilidade de horário de cada entrevistado. Os relatos foram gravados e, posteriormente, transcritos integralmente para subsequente análise de conteúdo com base na proposta de Bardin (2011).

Especificamente, no processo de compreensão das narrativas, foi utilizada a análise de conteúdo seguindo quatro momentos: 1. Esquema teórico e sua problemática; 2. Material de análise; 3. A análise; 4. Tratamento dos resultados. Dada a natureza desta análise, após a formação das categorias-síntese houve a definição destas. Em seguida, procedeu-se à revisão da definição das categorias, fase em que se contou com a participação de dois juízes com experiência em análise do conteúdo e familiaridade com o tema do presente estudo. Após essa etapa de concordância entre os juízes, obteve-se a definição das categorias.

\section{Resultados}

A partir da análise de conteúdo dos relatos de professores e gestores, foram categorizados três principais temas: 1) desconhecimento acerca do papel do psicólogo, 2) atuações do psicólogo escolar e 3) definição do papel do psicólogo. As categorias e as frequências dos relatos podem ser observadas na Figura 1. Ressalta-se que foram considerados os relatos dos participantes e não a quantidade de participantes.

\section{Desconhecimento do Papel do Psicólogo}

Foram incluídos nesta temática os relatos/falas e a manifestação de silêncio que indicaram o desconhecimento acerca do papel do psicólogo escolar $(n=4)$. Um desses relatos identificou o profissional de psicologia como sendo um profissional da área de serviço social. Os excertos abaixo exemplificam esta categoria:

Eu não sei falar muita coisa...

A G. é a assistente social daqui, então, não tenho nada a reclamar dela não, ela é ótima, mas assim, ela conversa com os alunos..., mas eu acho assim, ela é muito boa.

\section{Definição do Papel do Psicólogo Escolar}

Esta categoria refere-se aos relatos cujas concepções definiram o papel do psicólogo escolar, tendo sido construídas três subcategorias: especialista, auxiliar e indiferenciado. No tocante ao papel de 'especialista' $(n=21)$, os relatos indicaram o psicólogo escolar como detentor de um saber especializado e relevante, superando os saberes das outras profissões dentro do contexto escolar. Por exemplo:

...mas a gente não tem a formação que vocês [psicólogos] têm pra ter um atendimento perfeito que o aluno precisa. 


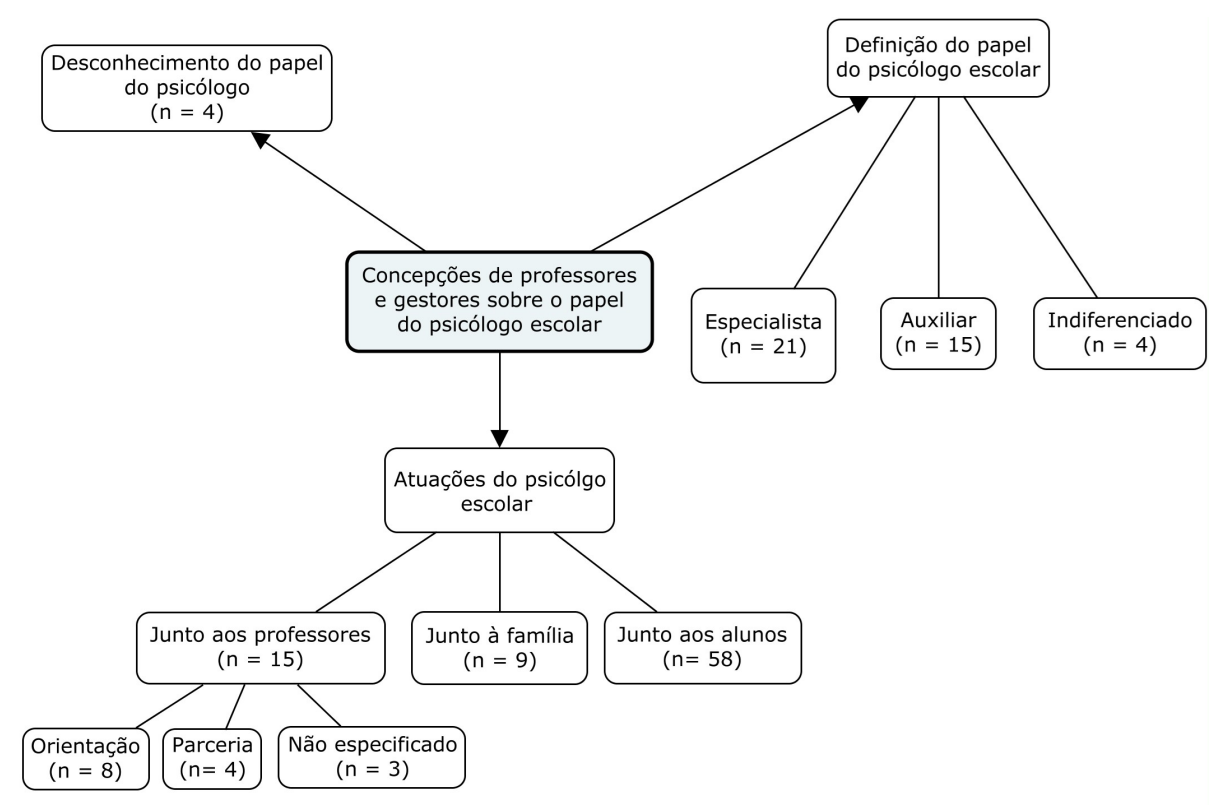

Figura 1. Concepções dos professores e gestores sobre o papel do psicólogo.

Em relação ao papel de 'auxiliar' $(n=15)$, isto é, o psicólogo como um profissional não essencial, sendo solicitado apenas quando necessário, foram identificados relatos como o que se segue:

...Eu vou te dizer assim... Às vezes não há tanta necessidade [do trabalho psicólogo escolar] porque eles são pequenos [os alunos]... e quando excede aquilo que é normal, do dia a dia, eu passo primeiro para a coordenação, pra minha coordenadora e, se for necessário, nós vamos até a psicóloga. E aí a gente até faz uma reunião com todos pra tentar resolver da melhor forma possível. Até agora não [precisei do psicólogo escolar], acho ótimo né, isso significa que todos estão bem.

A subcategoria 'indiferenciado' $(n=4)$ refere-se àqueles relatos que indicaram que as funções que os profissionais atribuem ao psicólogo também podem ser desempenhadas por outros profissionais da escola.

Eu acho que os professores são um pouquinho psicólogos porque eles [alunos] chegam pra gente contando alguns problemas em casa, nada muito grave não, mas eles sempre chegam contando alguma coisa e esperam da gente acesso.

\section{Atuações do psicólogo escolar}

Nesta categoria foram incluídas as falas/relatos que descreveram o psicólogo escolar em função de suas práticas direcionadas aos segmentos dentro da escola. Destaca-se que a frequência se refere ao número de relatos, podendo ser maior que o número de participantes. Essa foi a temática com maior frequência de relatos $(n=82)$, indicando que o psicólogo na escola é mais bem identificado por sua atuação individualizada junto aos alunos $(n=58)$. Os relatos identificando a ação do psicólogo junto aos professores $(n=15)$ e à família $(n=9)$ ocorreram com uma frequência um pouco menor. A Figura 2 mostra essas categorias e subcategorias. Nos relatos abaixo, identificam-se, por subcategoria, exemplos dos relatos dos participantes em relação à atuação junto aos alunos:

...o que eu percebo pode ser que seja um trabalho, assim, às vezes com aquelas crianças que têm mais dificuldade, tanto física quanto mesmo, assim, é, de aprendizagem né; não sei, alguma criança que tenha alguma necessidade educacional especial, um trabalho mais focado com aquela criança e também com outros alunos que tenham uma dificuldade, não sei. (Resolução de problemáticas)

... a turma estava com dificuldade de adaptação e eu pude contar com a parte da psicologia, que me ajudou pra caramba... fez uma observação e me ajudou muito, foi feito aquele sociograma, então foi muito bacana (Uso de técnicas)

No tocante às concepções de atuação do psicólogo junto aos professores, além dos relatos que somente apontaram para uma atuação com este segmento, sem ter havido especificação, seguem abaixo as duas outras subcategorias construídas: 


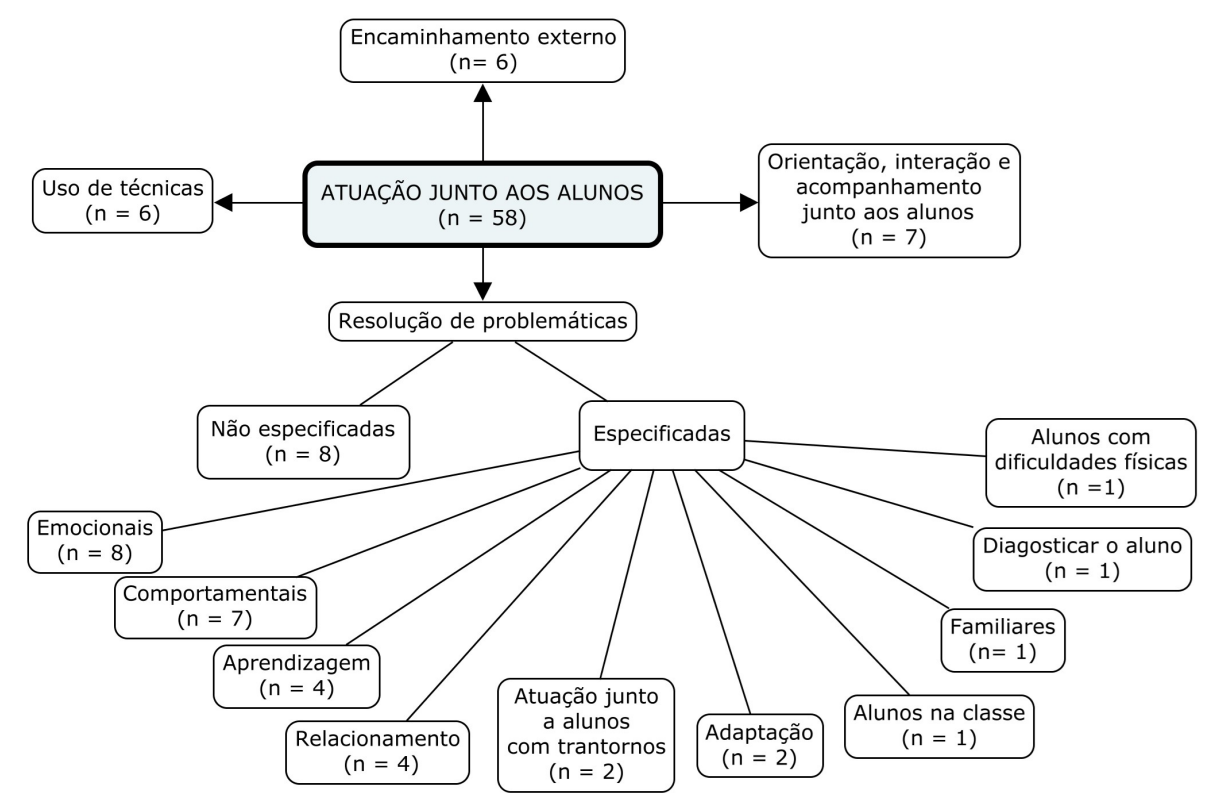

Figura 2. Atuações do psicólogo escolar junto aos alunos.

Assim, é que eu vejo como uma assistência, quando a gente tem alguma dificuldade, algum aluno que a gente vê que tá estranhando um pouco o ambiente ou tá com algum problema e a gente não sabe o que é, geralmente a psicóloga ajuda a gente bastante nesse ponto, pelo menos foi o que até hoje eu percebi. (Orientação)

...[o psicólogo] não é um balcão de tirar dúvidas, é uma parceria, cada um na sua área e no final das contas o ano letivo é o mesmo... (Parceria)

A atuação junto à família foi expressa nos relatos de que o psicólogo escolar pode conversar e dar apoio à família em assuntos que se referem a seus filhos, como pode ser verificado pelos relatos abaixo:

... agora nós temos a G. e assim, sempre que a gente [professores] precisa dela ou se uma mãe precisa, ela tá sempre pronta pra ajudar, pra conversar, pra entender e até pra dar alguma sugestão se for necessário pra essa mãe. Então é um apoio muito grande não só pra família...

... às vezes pai que chega aqui todo nervoso, você vai intervir, como psicólogo você vai ter muita voz ativa, entendeu?...

\section{Discussão}

Os resultados evidenciados no presente estudo, apesar de já terem sido alvo de discussões desde a década de 1970 (Patto, 1984), ainda permanecem atuais conforme apontado pela literatura (Antunes, 2008). As recentes discussões acerca dos aspectos teóricos e práticos da atuação do psicólogo escolar têm ressaltado a importância do desenvolvimento de perspectivas mais relacionais, que compreendam o espaço escolar de forma sistêmica. Sendo assim, práticas baseadas em um modelo clínico, de causalidade linear, que consideram na maioria das vezes o aluno-problema como foco de intervenção vêm sendo questionadas (Andrada, 2005; Lima, 2005; Giongo \& Oliveira-Menegotto, 2010). Apesar disso, tanto no estudo de Giongo e Oliveira-Menegotto (2010) quanto na presente investigação, os professores, naquele, e os professores e gestores, neste, ainda esperam que a prática do psicólogo escolar tenha o foco principal no aluno, indicando, portanto, que este é o problema e que apresenta aspectos disfuncionais, devendo ser 'tratado' de forma individual.

Os resultados da presente investigação mostram que os professores e os gestores concebem o trabalho do psicólogo escolar com foco nos alunos, tendo uma atuação voltada, principalmente, para as problemáticas dos discentes. Esse tipo de atuação está muito próximo de uma prática clínica e baseado em uma causalidade linear, por desconsiderar os diversos e inter-relacionados fatores que exercem influência no desenvolvimento do aluno e em seu desempenho acadêmico (Rodrigues \& cols., 2008). Além disso, essas concepções privilegiam mais a remediação, não havendo uma perspectiva de promoção e prevenção do desenvolvimento global do aluno, ênfase sustentada como fundamental por Rodrigues e cols. (2008). 
Segundo Selvini-Palazzoli e cols. (2004) é comum que os atores da escola busquem, junto ao psicólogo, uma intervenção, sendo habitual que essa procura se dê sempre para a resolução de um problema identificado no outro. Esse tipo de concepção é a que foi encontrada, com maior frequência, no presente estudo. Ressalta-se, portanto, que as ações do psicólogo no contexto escolar devem ser fundamentadas na concepção de um indivíduo como parte de sistemas relacionais, constituídos pela cultura e história. Além disso, é importante que os profissionais reconheçam a complexidade constitutiva dos indivíduos e dos processos sociais humanos, bem como das práticas sociais das quais a educação constitui uma expressão (Martinez, 2010).

A atuação junto aos professores e à família teve frequência menor, indicando, provavelmente, falta de clareza quanto ao papel do psicólogo escolar, conforme também encontrado em Costa e cols. (2012), mesmo considerando que o profissional estava presente naquele contexto. Nesse sentido, Andrada (2005) e Giongo e Oliveira-Menegotto (2010) sugerem que, a despeito dos avanços teóricos dentro do campo da psicologia escolar, a escola ainda possui a expectativa de uma atuação do psicólogo escolar voltada para o aluno desviante, isto é, aquele que se afasta da norma. Dessa forma, não é comum a professores e gestores a noção de um psicólogo que atue de forma institucional, articulando vários segmentos (estudantes, família, professores, diretores, etc.) em práticas ampliadas, conforme os resultados deste presente trabalho apontam.

Os resultados indicam também que os gestores e os professores identificam o psicólogo escolar como um 'especialista', ou seja, aquele que tem o conhecimento, saberes e habilidades únicas para resolver certas problemáticas do aluno, mas também como um profissional 'auxiliar', dispensável, mostrando que não há muita necessidade de seus serviços, podendo ser solicitado apenas nos momentos considerados difíceis ou insolúveis. Resultado similar foi encontrado por Rossetti e cols. (2004). Destaca-se que o presente estudo não pretendeu entrevistar o psicólogo sobre suas práticas, mas sim descrever as concepções dos profissionais da educação, as quais têm se mostrado alinhadas a um modelo mais reducionista de atuação.

Para que a posição ocupada pelo psicólogo escolar não seja a de especialista, aquele que, sozinho, resolverá "magicamente" os problemas na escola, é necessário que os problemas sinalizados sejam por ele compreendidos como dificuldades nas interações dentro dos diferentes subsistemas, isto é, professor-alunos, alunos-alunos, professores-direção etc., tendo em vista que estas se processam de forma coerente com os contextos no quais se encontram (Curonici \& McCulloch, 1999). Intervenções no âmbito da escola podem contribuir para o aumento do conhecimento da comunidade escolar acerca do papel do psicólogo.

Já a concepção de um profissional 'auxiliar' pode estar relacionada a certa rejeição à figura do psicólogo escolar, bem como ao próprio desconhecimento acerca da atuação desse profissional (Martinez, 2010). Destaca-se que é a partir da definição de suas potencialidades e limitações que o psicólogo deixará de ser o 'especialista', que sozinho tudo resolverá e, ao mesmo tempo, ao contribuir com o seu conhecimento, não será um profissional apenas 'auxiliar' ou que pode ter suas funções desempenhadas por outros profissionais, mas um membro importante e integrante da escola que deve trabalhar em conjunto, em equipe.

Como destacam Selvini-Palazzoli e cols. (2004), é importante que cada membro da equipe escolar reflita sobre a sua responsabilidade e participação, tanto os professores e coordenadores, quanto o próprio psicólogo e que este ocupe a sua posição e, nessa medida, tenha o seu trabalho reconhecido. Segundo Martinez (2010), discussões em torno do papel do psicólogo escolar se mostram positivas e promissoras para que haja uma manifestação de uma mudança gradual indo de um modelo de atuação tradicional para um modelo de atuação mais amplo e diverso.

Tais questões trazem à tona a importância do trabaIho colaborativo entre o psicólogo e a equipe de trabalho, o que contribui para que a atuação do psicólogo escolar seja eficiente e não se torne uma ameaça para o trabalho e espaço de outros profissionais (Martinez, 2010). Quando o psicólogo trabalha colaborativamente com toda a escola é retirado dele o peso de especialista, bem como as expectativas irrealistas quanto às suas possibilidades de atuação; dessa forma, as responsabilidades são compartilhadas e assumidas por todos e o psicólogo se torna um importante gerenciador de relações (Curonici \& McCulloch, 1999). É de suma importância que o psicólogo se integre à equipe escolar, assumindo planos/propostas de superação profissional, isto é, propostas de atuação alinhadas às reais condições de trabalho e integradas à comunidade escolar, proporcionando uma contribuição, de fato, para a escola em que trabalha (Martinez, 2010).

\section{Considerações finais}

É importante destacar que os resultados apresentados refletem a concepção de professores e gestores de uma única escola de uma cidade do interior de Minas Gerais, portanto as discussões aqui realizadas não pretendem generalizar tais ideias, mas refletir acerca do papel do psicólogo escolar na atualidade. Inicialmente, destaca-se a importância da formação profissional do psicólogo para atuação no campo da Educação. Formação que deve estar comprometida com uma prática social e, principalmente, pautada pela compreensão do processo ensino-aprendizagem e sua articulação com o desenvolvimento, conforme aponta Antunes (2008).

Parece ser um desafio para o psicólogo mergulhar na esfera da Educação. Entretanto, ele (a) é o(a) profissional que apresenta as ferramentas capazes de propiciar o diálogo interdisciplinar e favorecer os processos sócio institucionais da escola. Ressalta-se ainda que a implementação de investigações é necessária, com maior número de participantes e em contextos escolares diversos, tais como escolas públicas e privadas. Investigações com alunos, por exemplo, são es- 
cassas. Assim, considera-se que o primeiro passo para a compreensão do papel do psicólogo em tempos atuais, seja por meio de investigações empíricas que possam embasar as reflexões mais ampliadas.

\section{Referências}

Andaló, C. S. A. (1984). O papel do psicólogo escolar. Psicologia: Ciência e Profissão, 4(1), 43-46.

Andrada, E. G. C. (2005). Novos paradigmas na prática do psicólogo escolar. Psicologia Reflexão e Crítica, 18(2), 196-199.

Antunes, M. A. M. (2002). Psicologia e educação em periódicos brasileiros anteriores a 1962. Psicologia Escolar e Educacional, 6(2), 193-200.

Antunes, M. A. M. (2008). Psicologia Escolar e Educacional: História, compromissos e perspectivas. Psicologia Escolar e Educacional, 12(2), 469-475.

Antunes, M. A. M. (2012). A Psicologia no Brasil: Leitura histórica sobre sua constituição. São Paulo: Educ.

Barbosa, R. M. (2010). Psicologia escolar no Brasil: Considerações e reflexões históricas. Estudos em Psicologia, 27(3), 393-402.

Bardin, L. (2011). Análise de conteúdo. São Paulo: Edições 70.

Bray, C. T. (2015). A atuação de psicólogos na rede particular de ensino: possibilidades, limites e superações. Tese de doutorado, Universidade de São Paulo, Instituto de Psicologia, São Paulo.

Carvalho, T. O. \& Marinho-Araújo, C. M. (2009). Psicologia Escolar no Brasil e no Maranhão: Percursos históricos e tendências atuais. Psicologia Escolar e Educacional, 13(1), 65-73.

Costa, G. C., Sanhueza, G. C., Barra, M. M., \& Villalobos, C. P. (2012). Rol del psicólogo em establecimientos particulares pagados del Gran Concepción, Chile: Un proceso de co-construcción. Estudios Pedagógicos, 2, 169-185.

Cruces, A.V.V. (2005). Práticas emergentes em psicologia escolar: nova ética, novos compromissos. Em A.M. Martinez (Org.), Psicologia escolar e compromisso social: novos discursos, novas práticas (pp. 47-65). Campinas: Alínea.

Curonice, C. \& McCulloch, P. (1999). Psicólogos \& professores: Um ponto de vista sistêmico sobre as dificuldades escolares. Bauru, SP: EDUSC.

Farrell, P. (2009). El Papel en desarrollo de los psicólogos escolares y educativos en el apoyo a niños, escuelas y familias. Papeles del psicólogo, 30(1), 74-85.

Firbida, F. B. G. \& Facci, M. G. D. (2015). A formação do psicólogo no estado do Paraná para atuar na escola. Psicologia Escolar e Educacional,19(1), 173-184.

Fraser, M. \& Gondim, S. (2004). Da fala do outro ao texto negociado: Discussões sobre a entrevista na pesquisa qualitativa. Paidéia, 14(28), $139-152$.

Giongo, C. \& Oliveira-Menegotto, L. M. (2010). (Des)enlaces da psicologia escolar na rede pública de ensino. Psicologia USP, 21(4), 859-874.

Goulart, I. B. (2003). Psicologia da Educação: Fundamentos teóricos e aplicações à prática pedagógica. Petrópolis: Vozes.

Graves Jr., S. L., Proctor, S. L., \& Aston, C. (2014). Professional roles and practices of school psychologists in urban schools. Psychology in the Schools, 51(4), 384-394.

Guzzo, R. L. S., Mezzalira, A. S. C., Moreira, A. P. G., Tizzei, R. P., \& Neto, W. M. F. S. (2010). Psicologia e Educação no Brasil: Uma visão da história e possibilidades nessa relação. Psicologia: Teoria e Pesquisa, 26, 131-141.

Guzzo, R. S. L. (2003). Saúde psicológica, sucesso escolar e eficácia da escola: desafios do novo milênio para a psicologia escolar. Em Z. A. P. Del Prette (Org.), Psicologia escolar e educacional, saúde e qualidade de vida: explorando fronteiras (pp. 25-42). Campinas: Alínea.

Kub, J. \& Feldman, M. A. (2015). Bullying prevention: A call for collaborative efforts between school nurses and school psychologists. Psychology in the School, 52, 658-671.

Lessa, P. V. \& Facci, M. G. D. (2011). A atuação do psicólogo no ensino público do Estado do Paraná. Psicologia Escolar e Educacional,15(1), 131-141.

Lima, A. O. M. N. (2005). Breve histórico da psicologia escolar no Brasil. Psicologia Argumento, 23(42), 17-23.

Marinho-Araújo, C. M. \& Almeida, S. F. C. (2005). Psicologia escolar: Construção e consolidação da identidade profissional. Campinas, SP: Alínea.

Martinez, A. M. (2010). O que pode fazer o psicólogo na escola? Em Aberto, 23(83), 39-56.

Martínez, M. (2006). La investigación cualitativa (síntesis conceptual). Revista IIPSI, 9(1), 123-146.

McGraw, K. \& Koonce, D.A. (2011). Role of the school psychologist: Orchestrating the continuum of school-wide positive behavior support. Communique, 38(8), 4-8.

Neves, M. M. B. J., Almeida, S. F. C., Chaperman, M. C. L., \& Batista, B. P. (2002). Formação e atuação em psicologia escolar: Análise das modalidades de comunicações nos congressos nacionais de 
psicologia escolar e educacional. Psicologia: Ciência e Profissão, 22(2), 2-11.

Oliveira, C. B. E. \& Marinho-Araújo, C. M. (2009). Psicologia escolar: Cenários atuais. Estudos e Pesquisas em Psicologia, 9(3), 648663.

Patto, M. H. (1984). Psicologia e ideologia: uma introdução crítica à psicologia escolar. São Paulo: T. A. Queiroz.

Rodrigues, M. C, Itaborahy, C. Z., Pereira, M. D., \& Gonçalves, T. M. C. (2008). Prevenção e promoção de saúde na escola: Concepções e práticas de psicólogos escolares. Gerais: Revista Interinstitucional de Psicologia, 1(1), 67-78.

Rossetti, C. B., Silva, C. A., Batista, G. L., Stein, L. A., \& Hulle, L. de O. (2004). Panorama da Psicologia Escolar na cidade de Vitória: um estudo exploratório. Cadernos de Psicologia e Educação Paideia, 14(28), 191-195.

Selvini-Palazzoli, M., Cirillo, S., D'etorre, L., Garbellini, M, Ghezzi, D., Lerma, M., Lucchini, M., Martino, C., Mazzucchelli, F., \& Nichele, M. (2004). El mago sin magia: Cómo cambiar la situación paradójica del psicólogo en la escuela. Buenos Aires: Paidós.

Sherer, Y. C., \& Nickerson, A. B. (2010). Anti-bullying practices in American schools: Perspectives of school psychologists. Psychology in the Schools, 47(3), 217-229.
Souza, B. P. (2007). Apresentando a Orientação à Queixa Escolar. Em B. P. Souza (Org.), Orientação à queixa escolar (pp. 97-118). São Paulo: Casa do Psicólogo.

Souza, C. S., Ribeiro, M. J., \& Silva, S. M. (2011). A atuação do psicólogo escolar na rede particular de ensino. Psicologia Escolar e Educacional, 15(1), 53-61.

Souza, M. P. R. (2009). Psicologia Escolar e Educacional em busca de novas perspectivas. Psicologia Escolar e Educacional,13(1), 179-182.

Souza, M. P. R., Gomes, A. M. M., Cecchia, A. K. A., Lara, J. S. A., \& Roman, M. D. (2016). Psicólogos em secretarias de educação paulistas: concepções e práticas. Psicologia Escolare Educacional, 20(3), 601-610.

Valles, M. (1999). Técnicas cualitativas de investigación social. España: Síntesis S.A.

Watkins, M. W., Crosby, E. G., \& Pearson, J. L. (2001). Role of the school psychologist: Perceptions of school staff. School Psychology International, 22, 64-73.

\section{Sobre as autoras}

Nara Liana Pereira-Silva (naraliana.silva@ufjf.edu.br)

Doutora em Psicologia, Universidade Federal de Juiz de Fora - MG.

Recebido em: 21 de junho de 2016

Aprovado em: 7 de maio de 2017

Jaqueline Ferreira Condé de Melo Andrade (jaquelinecondemelo@gmail.com)

Mestre em Psicologia, Universidade Federal de Juiz de Fora - MG.

Sarah Rezende Crolman (sarahcrolman@hotmail.com)

Mestranda em Psicologia, Universidade Federal de Juiz de Fora - MG.

Cristina Fuentes Mejía (krisfmejia16@hotmail.com)

Doutoranda em Psicologia, Universidade Federal de Juiz de Fora - MG. 